\title{
The Sports Participation: From Research to Sports Policy
}

Authors' contribution:

A) conception and design of the study

B) acquisition of data

C) analysis and interpretation of data

D) manuscript preparation

E) obtaining funding

\section{Núria Puig}

National Institute of Physical Education of Catalonia, Spain

KEYWORDS

\begin{abstract}
The aims of this paper are the following: 1 . To provide an overview of the fundamental aspects to be taken into account when carrying out and interpreting sports participation surveys; 2 . To put forward an explanation of sports behavior; and 3. To suggest how these results may be used in intervention programs. Having gone over the literature in this field, I shall go on to address the following points: the definition of sports; trend analysis or the illusion of transparency; analysis of inequalities; identifying difference and individualization; and examining typologies to better understand each social group. I shall conclude with suggestions for sports policies.

sports policies, sports participation, typologies, social inequalities
\end{abstract}

\section{ABSTRACT}

\section{Introduction}

The idea that sports must be examined in changing social, economic, political, and cultural contexts denotes the close relationship that exists between sports and their context. The deep changes currently taking place in Europe, for example, call for precise knowledge of the circumstances of sports participation in order to devise programs that satisfy new needs.

"Policy demands research to back up choices that need to be made, relying on data to be gathered, mechanisms to be detected, and interventions to be proven effective" (Hoekman et al., 2011, p. 7).

There is a long tradition of surveys and studies on sports participation. For some years now, many countries have been conducting surveys to ascertain their respective degrees of sports participation. It is only by having this information available to us that we may establish sports policies geared towards fostering people's access to sports.

In my view, there are three kinds of studies that complement each other and allow us to make progress in this field:

1. Surveys, in the strict sense, complete with their corresponding reports. These are conducted in each country, and, since 2004, the Eurobarometer on sports has offered comparative data for EU countries (European Commission, 2004). In addition to the survey from 2004, we now have those from 2010 and 2014, a highly enriching contribution which allows us to begin analyzing trends in Europe as a whole (European Commission, 2010, 2014). 
2. The initiatives that emerged in Europe before the advent of the Eurobarometer with the intention of comparing data from national surveys conducted in accordance with different criteria and rationalizing sports policies. An initial set of studies was carried out within the framework of the European Council (Castejón Paz et al., 1973; Claeys, 1982a, 1982b; Rodgers, 1977, 1978). Next came the COMPASS (Coordinated Monitoring of Participation in Sports) project, originally an Anglo-Italian initiative (UK Sport, 1999). Like the previous studies, the COMPASS project focused above all on improving the comparability of sports participation research in Europe. In 2005, Van Bottenburg et al. published a study on sports participation in Europe. In 2010, the MEASURE group was formed, composed of experts from many European countries, with the aim of improving the understanding of sports participation differences, upgrading the quality of sports participation data, and fostering knowledge exchange. These studies, though based on surveys and, originally, on problems of comparison, have gradually built up a corpus of theoretical knowledge that foments a better understanding of sports participation characteristics.

3. Theoretical studies that focus on sports participation. These studies serves as a basis for identifying factors that should be taken into account when conducting surveys; they also offer elements that contribute to the correct interpretation of survey results. Though a great deal of literature exists that may be included in this section, I shall limit my references to the studies I have most often turned to myself - not that it is my wish to exclude other contributions of considerable interest. McPherson's reflections on "Sport Participation Across the Life Cycle", written in 1984, still strikes me as being highly useful for understanding variations in sports conduct as people become socialized (McPherson, 1984). Heinemann (2007) proposes a model by which we can understand the decisive factors involved in sports participation; furthermore, in this context he provides an overview of all the aspects that contribute to a better understanding of the data provided by surveys. Lastly, I should highlight the contributions from a number of authors to the special issue of the European Journal for Sport and Society on "Sport Participation in Europe", published in 2011 (Hoekman et al., 2011).

On the basis of these three kinds of contributions, I would like to examine a number of aspects that strike me as being essential for designing or interpreting sports participation surveys. I have also based my observations on my experience as director of the Observatori Català de l'Esport (http://www.observatoridelesport.cat); the observatory conducted two surveys on sports participation in Catalonia and prepared the corresponding indicators, which appear on our website (Puig et al., 2009; Secretaria General de l'Esport, 2010). In addition, I have based my observations on my extensive teaching experience in the sociology of sports at the National Institute of Physical Education of Catalonia (Institut Nacional d'Educació Física de Catalunya [INEFC]); over a period of almost forty years, I have taught my students the basic concepts of sports participation analysis. Lastly, I have incorporated my experience as a director of the research projects of the GISEAFE (Grup d'Investigació Social i Educativa en Activitat Física i Esport; http://www.inefcgiseafe.wordpress.com) at the INEFC in Barcelona.

\section{Objectives}

The aims of my paper are the following:

1. To provide an overview of the fundamental aspects to be taken into account when conducting and interpreting sports participation surveys.

2. To put forward an explanation of different kinds of sports behavior that would encompass alldetermining variables while also facilitating sports policy planning.

3. To make suggestions as to how these results may lead to intervention programs geared towards fostering and increasing sports participation. 


\section{Definition}

In order to ascertain how many people engage in sports, we must first decide what we understand the meaning of sports to be. It is a well-known fact that there are many definitions of this concept, and many different opinions emerge upon discussion of the issue. However, in order to begin, we must reach an agreement on a nominal or operative definition of sports. We must find a valid option from which to undertake research, and, as Heinemann suggests, these definitions

"determinations or conventions regarding the content of concepts (...), are necessary because, on the one hand, they serve to endow communication with clarity and, on the other, to delimit the object of research" (Heinemann, 2003a, p. 62).

Many of the differences observed between surveys conducted either in different countries or in the same country by different teams are not real; the simple fact is that they are a response to what may have been a wider conception of sports (which would include less regulated activities) or a narrower one (grounded on a more traditional definition of sports). For some years now, there has been an agreement to adopt the definition of sports that appears in the 1992 European Sports Charter, which reads as follows: “'Sport' means all forms of physical activity which, through casual or organised participation, aim at expressing or improving physical fitness and mental well-being, forming social relationships or obtaining results in competition at all levels".

Even so, we have to determine where the limits to this definition lie, since, in operative terms, many aspects remain to be clarified. For example, it has yet to be decided whether walking, or even an activity such as gathering mushrooms, may be included in the definition of sports; this issue was raised at a COMPASS project meeting some years ago.

In the 2014 Eurobarometer decisions were taken, and the questions on whether or not people engage in sports (regardless of regularity or forms of engagement) remain as follows:

1. The first question is: How often do you exercise or practice sports?

In order to avoid confusion, the people conducting the survey (on a face-to-face basis) added the following clarification: By "exercise", we mean any form of physical activity which you do in a sports context or sports-related setting, such as swimming, training in a fitness center or a sports club, running in the park, etc.

2. The delimitation of the concept is specified in the following question: How often do you engage in other physical activities such as cycling from one place to another, dancing, gardening, etc.?

In this case, the specification was: By "other physical activity", we mean physical activity for recreational or non-sports-related purposes.

These physical exercise activities are good for the health and, as such, should be fostered within the framework of policies for well-being. Furthermore, it would be desirable to ascertain conduct in the context of these activities; however, they are differentiated from what has been defined as sports in the Eurobarometer.

3. The same occurs with walking. There are countries in which much importance is attached to this activity, and, once again, it is also healthy when done frequently. The corresponding question reads as follows: Over the last seven days, on how many of these days have you walked for at least 10 minutes at a time?

It is essential for us to make these decisions so that we know exactly what we are measuring and so that we can make trend analyses, the most important factor in devising sports policy. These aspects were not taken into account in the Eurobarometer, and the 2014 questions differ from those of 2004 and 2010. If these aspects are not known, negative interpretations may be made of the data obtained from the surveys. I am referring in particular to the question concerning "other physical activities", which included walking in 2010, but was differentiated in the 2014 version. Following is the resulting table (Table 1): 
Table 1. Sports participation in Europe (in \%)

\begin{tabular}{lcc}
\hline & $\mathbf{2 0 1 0}$ & $\mathbf{2 0 1 4}$ \\
\hline Sports (once a week) & 40 & 41 \\
Other physical activity & 65 & 48 \\
Walking & - & 86 \\
\hline
\end{tabular}

Source: own study based on European Commission, 2010, 2014.

If we did not know that the concepts had been delimited differently, we might conclude that between 2010 and 2014, participation in other physical activities underwent a dramatic decline (from 65\% to 48\%). Even after taking specific precautions, it is still doubtful that what we are measuring has the same meaning for all the target countries or territorial areas. For example, Stamm and Lamprecht, referring to Switzerland, conclude that different definitions of sports in the national and cultural context might be the reason for differences in sports participation rates between the linguistic regions (Stamm, \& Lamprecht, 2011).

A similar observation might be made regarding the results from surveys on walking. When we examine the tables in the appendix of the 2014 Eurobarometer report, we are astonished to see that Spain ranks number one. A total of $76 \%$ of the people who took part in the survey stated that they walk between four and seven days a week for at least 10 minutes, and, of these, $43 \%$ do so for at least one hour. A survey conducted in Spain corroborates these findings (García Ferrando, \& Llopis, 2011, pp. 100-102). The explanation for this, however, is that in Spain the paseo, or stroll, is practically a national pastime. It is an activity deeply anchored in tradition and is now regarded as a healthy custom that has existed since time immemorial, especially for adults and the elderly. After lunch, housewives go out for a stroll, and in the evening, when their husbands return from work, the couple goes out for a stroll before supper, chatting about their respective days, seeing and being seen. It is a daily ritual deeply rooted in Spanish society. This fact has very different cultural roots from those of sports participation, for which our country occupies a midway position in the European ranking. Walking and the paseo are different things, and surveys (governed by quantitative methods par excellence) are unable to reflect these kinds of nuances.

\section{Trend analysis or the illusion of transparency}

Trend analysis must be undertaken with great caution, for errors may also be made in this area due to a lack of theoretical perspective. In such cases, I like to speak of the illusion of transparency, as do Bourdieu et al. in their book The Craft of Sociology (Bourdieu et al., 1991, p. 30). According to these authors, we cannot allow ourselves to be carried away by common-sense interpretations; rather, such interpretations must be based on a theory of social knowledge.

One highly revealing example in this context has to do with sports participation according to age group. Time after time we hear that "Sport participation progressively and steadily diminishes as people get older" (Rodgers, 1977, p.18), and

"The amount of regular activity that people do tends to decrease with age, notably $71 \%$ of women and $70 \%$ of men in the 55+ age groups never or seldom exercise or play sport" (European Commission, 2014, p. 7) ${ }^{1}$,

then follow recommendations aimed at dissuading the elderly from giving up sports.

The mistake is made of interpreting data that compare age groups without conducting a longitudinal follow-up of the same groups. Actually, it is not that older people give up sports because of biological problems; in fact, in most cases they never engaged in sports in the first place, which is explained by the cohort effect (Hartmann-Tews, 2006, p.116; Heinemann, 2007, p. 243; McPherson, 1984, p. 220). Today's elderly were brought up at a time when sports did not yet enjoy a high degree of development and sports promotion campaigns were few and far between. During their youth, many of these people lived through

\footnotetext{
${ }^{1}$ This quote may be interpreted in terms of either of the two options I have pointed to here. I have been unable to deduce which of the interpretations the report refers to by simply reading it.
} 
a war and were subsequently forced to struggle their way through the post-war period. Therefore, given the peculiarities of the socialization of this generation, they were hardly in the optimum position to develop a sports culture. The interesting fact, however, is that as their quality of life gradually improved, these people began to engage in sports when they reached old age; furthermore, those who did so figure among the groups who practice sports most regularly and enthusiastically (European Commission, 2014).

Thus, the representation and interpretation of sports participation trends according to age group may vary considerably, depending on the way they are approached. Let us look at one example. I have chosen not to use data from the 2004, 2010, and 2014 Eurobarometers due to the corresponding variations in the way the questions were formulated, as these variations make me doubt their comparability. I therefore have decided to use data from the surveys that were conducted in Spain every five years from 1980 to $2010^{2}$.

If we represent sports participation according to age in a line graph, the result can very easily be misinterpreted, as I have described above. We may conclude that as people get older, they cease to engage in sports. This kind of representation conceals the cohort effect (Figure 1).

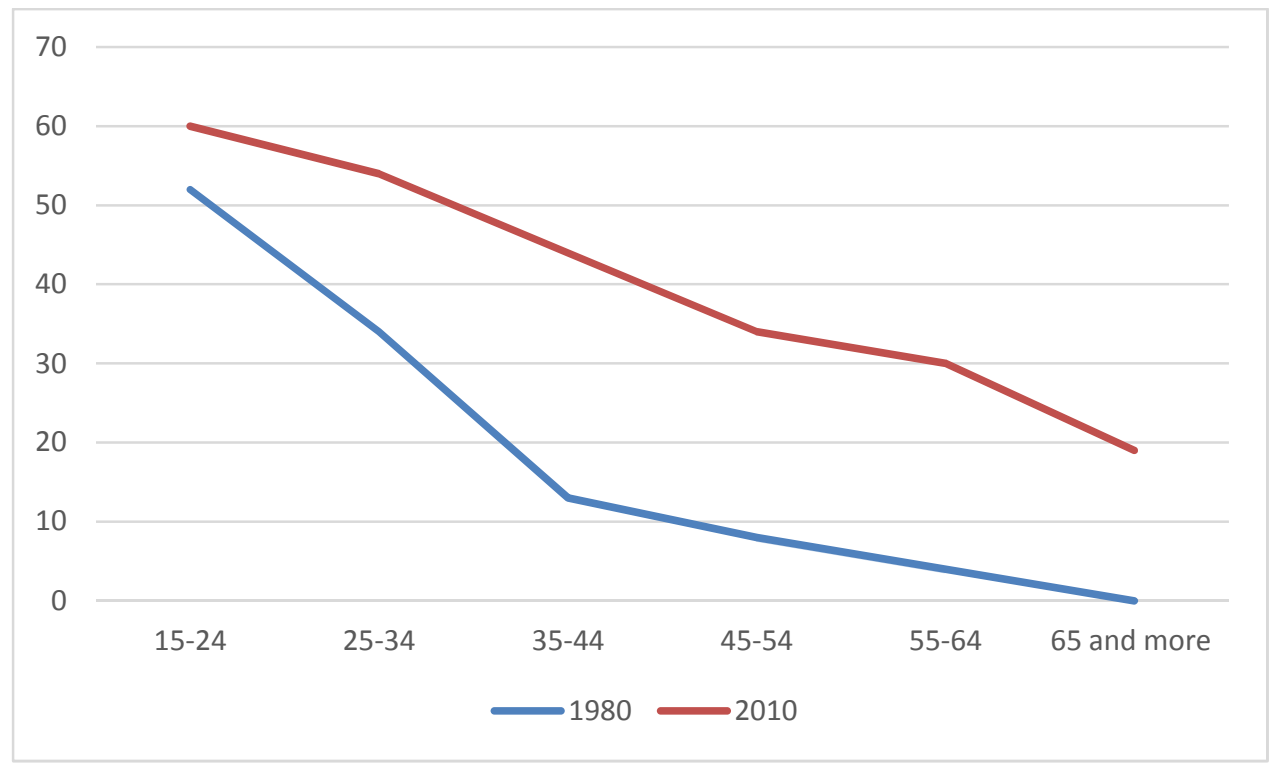

Figure 1. Sports participation in Spain according to age (in \%)

Source: own study based on García Ferrando, \& Llopis 2011, p. 53.

However, if we make a column figure (Figure 2), we can clearly see that sports participation increased considerably between 1980 and 2010 for each age group, including that of the elderly. The cohort effect is clearly represented; what it reveals is that people who began to engage in sports in their youth continue to do so throughout their lives (Hartmann-Tews, 2006, p. 116; Heinemann, 2007, p. 243; McPherson, 1984, p. 220).

\footnotetext{
${ }^{2}$ At the time of writing this article, the results of the 2015 survey were about to be made public.
} 


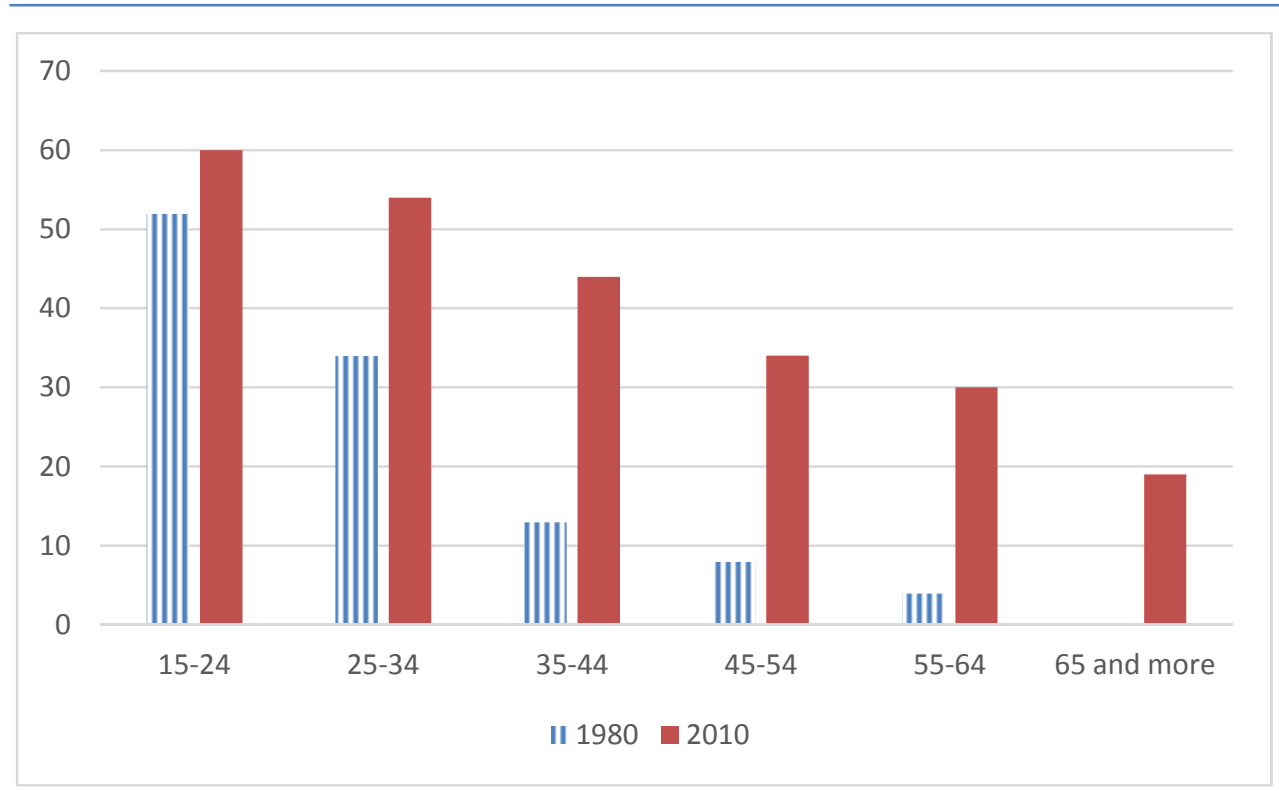

Figure 2. Sports participation in Spain according to age (in \%)

Source: own study based on García Ferrando, \& Llopis 2011, p. 53.

\section{Inequality analysis}

When we analyze sports participation in accordance with independent variables, different forms of inequality in access to sports immediately come to light. Women practice sports less than men. People with a higher educational level and social status engage in sports more than people with a low level in these two categories. These results are repeated survey after survey in all surveyed countries. Despite all efforts to the contrary, discrimination still takes place when it comes to acceding to social facilities - in this case, sports. As these issues are common knowledge, I shall not dwell on them here.

What I do want to stress is the fact that the variables I mention above do not act in isolation from each other; on the contrary, they are interdependent. Women with higher education engage in sports almost to the same extent as men of the same level; elderly people with higher education engage in sports more often than young people with only primary studies, and so on. Thus, sports participation is actually linked to socialization and the values acquired during the socialization process, as well as to the habitus acquired throughout life, which is associated with class origins. People with higher social status have a culture that leans towards an athletic lifestyle, hence the fact that they take greater advantage of sports opportunities when they become available (Boltanski, 1971; Heinemann, 2007). Paradoxically enough, they are often even the first to learn of these offers and to benefit from them. Sports is by no means extraneous to mechanisms of social reproduction.

Following is an example of what I am commenting on; this case refers to Catalonia (Table 2).

Table 2. Sports participation according to age and educational level in Catalonia (in \%)

\begin{tabular}{|c|c|c|c|c|c|c|}
\hline & $15-24$ & $25-34$ & $35-44$ & $45-54$ & $55-64$ & 65 or over \\
\hline Primary school & $\%$ & $\%$ & $\%$ & $\%$ & $\%$ & $\%$ \\
\hline Practice sports & 56.7 & 37.9 & 40.8 & 46.2 & 53.2 & 48.8 \\
\hline \multirow[t]{2}{*}{ Do not practice sports } & 43.3 & 62.1 & 59.2 & 53.8 & 46.8 & 51.2 \\
\hline & $(202)$ & $(69)$ & $(182)$ & $(148)$ & $(166)$ & $(190)$ \\
\hline Higher education & $\%$ & $\%$ & $\%$ & $\%$ & $\%$ & $\%$ \\
\hline Practice sports & 58.6 & 64.5 & 59.7 & 57.3 & 63.7 & 58.1 \\
\hline \multirow[t]{2}{*}{ Do not practice sports } & 41.4 & 35.5 & 40.3 & 42.7 & 36.3 & 41.9 \\
\hline & $(42)$ & (118) & (188) & (98) & $(69)$ & (46) \\
\hline
\end{tabular}

Source: own study based on Secretaria General de l'Esport 2009. 
This table confirms my above-mentioned conclusions: people aged 65 years old and over with higher education engage in sports $(58.1 \%)$ more than young people aged $15-24$ years old with only primary studies $(56.7 \%)$.

It is crucial to keep this in mind when planning intervention policies and identifying target groups in their totality, rather than through isolated variables.

\section{Identifying difference and individualization}

When we identify inequality, we must also identify difference. Although this concept was put forward as part of feminist theory, it is of great use when it comes to analyzing social relations as a whole. Theories of difference are understood as the way we approach the life of people on the basis of their individuality, or who they are, rather than how they compare with other men or women (Balbo, 1999; Subirats, 1998). In the case of gender relations, it is a matter of understanding the world of women from their experiences, their meaning attributions, their culture, their traditions - in short, it is a matter of highlighting female individuality.

When we analyze the practice of sports in terms of gender, we must take into account the fact that the differences observed are not only quantitative, but also qualitative. Survey results show that men and women are characterized by different forms of sports behavior, which reflects habits and values acquired during the socialization process. We must therefore bear female and male sports cultures in mind in order to understand the worlds both genders experience.

The 2014 Eurobarometer allows us to take this approach, except in the case of the most widely practiced sports, which it does not evaluate. I propose the following graphic representation (Figure 3):

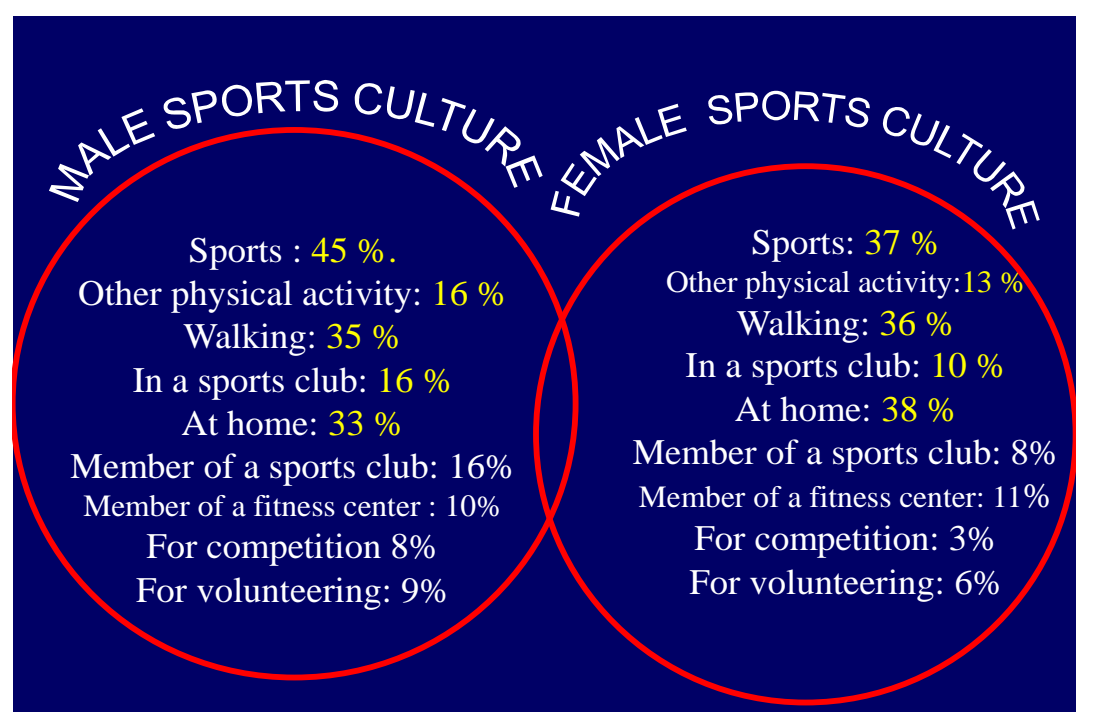

Figure 3. Two sports cultures

Source: own study based on based on European Commission, 2014.

Quantitative data provide us with material from which we can draw qualitative conclusions. Differences diminish when other physical activities (3\%), or walking (1\% more in the case of women), are considered instead of focusing on sports (8\% difference). These activities come closer to traditional female stereotypes, with which women tend to identify to a greater degree. In the context of the customary spaces of socialization, women practice more at home than men (38\% compared with 33\%), while men participate in sports clubs more often than women (16\% compared with $10 \%)$. It is also more common for men to be members of a sports club if their everyday habits are more in line with the club's time schedule (16\% compared with $8 \%)$. This reasoning also explains why more women join fitness clubs than men (11\% as 
opposed to $10 \%$ ). The motives that prompt men and women to engage in sports also vary; here, I would pinpoint the desire to compete, which, although low in both cases, is much higher among men (8\% compared with 3\%). Lastly, more men (9\%) than women (6\%) take part in volunteering, and, once again, what is most interesting here is the kind of volunteering both genders engage in:

\begin{abstract}
"Men are more likely than women to be coaches or trainers (33\% compared with 23\%), to be referees or officials (11\% compared with 6\%), and to maintain sport facilities (12\% compared with 6\%). By contrast, women are more likely to do administrative tasks $(21 \%$ compared with $13 \%)$, support day to day club activities (23\% compared with 18\%) and provide transport (18\% compared with 14\%). In particular, support for day to day club activities and providing transport are more likely to be provided by women in the middle age bands (25-39 and 40-54) and those with children" (European Commission, 2014, p. 76).
\end{abstract}

Here, we can clearly appreciate the profiles linked to values acquired during the socialization process and, to a greater degree, to everyday life, if we bear in mind the fact that school transport is provided by mothers and, likely, young grandmothers. They combine their family obligations with volunteering.

Nonetheless, with regard to the two cultures I mentioned earlier, I must stress that nowadays, we tend to take an excessively simplistic view unless we take into account the impact of the individualization process on gender-associated stereotypes.

For Bette (1995), the individualization process provides greater autonomy vis-à-vis the weight of social institutions, which traditionally mapped out the system of values and rules to be followed. While these certainly offered security (there was no need for men or women to make their own decisions), they were far more restricting in terms of individual freedom. Modernization has weakened assigned status, assigned social positions, "and may transform personal biographies into a battlefield where individual decisions clash with social developments" (Bette, 1995, p. 35).

Therefore, we must ensure that our data analysis reflects this twofold dimension in terms of conduct: hegemonic trends on the one hand and emerging developments as a consequence of the individualization process on the other. Furthermore, such analysis cannot be conducted solely from the gender perspective; it must encompass all the sociodemographic variables that characterize social groups. In this context in Spain, we have opted for establishing typologies of people who engage in sports, through which I believe we reflect the everyday lives of people and the particularities of their conduct by encompassing everything in one single analysis: age, gender, educational level, socio-professional level, and other major variables.

\title{
The use of typologies to better understand each social group
}

The analysis of the sports practice variable segmentation is a statistical procedure that reveals the interdependence of variables which I have referred to above; moreover, it explains which variables have the greatest influence on engagement or non-engagement in sports. Such analysis progressively distinguishes between these variables until it eventually establishes a set of typologies for people who engage in sports. In these sets, we may include all the independent variables which are normally analyzed separately. On several occasions, García Ferrando has used this procedure to determine the typologies of people who engage in sports (García Ferrando, \& Llopis, 2011, pp. 247-251). At the Observatori Català de l'Esport, we applied it to an analysis of the 2009 survey on sports habits (Secretaria General de l'Esport, 2010). As I do not have the Eurobarometer database from which to conduct an analysis at the European level, I shall use the observatory study as an example. The graphic representation of this segmentation procedure can be seen on page 54 of the observatory's 2009-2010 publication (http://php.inefc.net/observatori/docus/estudis_publicats/OCE_10_estudis_publicats_ca.pdf).

According to this graphic, the socio-professional category is the first variable that discriminates between groups of people who engage in sports. Broadly speaking, there are three major groups: qualified workers, unskilled workers, and liberal professionals. In the first case, we find further discrimination caused by educational level: unifinshed primary school, secondary school, and university studies. Lastly, in the 
secondary education bracket, gender is the last discriminatory variable. In the group of liberal professionals, the second and last differentiations are due to gender This also occurs with the group of unskilled workers; furthermore, further differentiation occurs in the case of women due to age: those 45 years old and over and those under 45 years old. In total, we have nine groups of people who engage in sports. In Table 3, they are grouped together in descending order by the regularity with which they practice sports.

Table 3. Typologies of people who engage in sports in Catalonia in accordance with sports practice variable segmentation analysis

\begin{tabular}{clc}
\hline Group & \multicolumn{1}{c}{ Profile } & \% engagement \\
\hline $\mathbf{1}$ & Men, liberal professionals (high degree of occupation) & 68.4 \\
$\mathbf{2}$ & Men and women, skilled workers, higher education & 60.3 \\
$\mathbf{3}$ & Women, liberal professionals (high degree of occupation) & 55.1 \\
$\mathbf{4}$ & Men, skilled workers, secondary education & 53.4 \\
$\mathbf{5}$ & Men, unskilled workers & 48.6 \\
$\mathbf{6}$ & Women, unskilled workers, aged 45 and over & 41.5 \\
$\mathbf{7}$ & Women, skilled workers, secondary education & 40.8 \\
$\mathbf{8}$ & Men and women, skilled workers, unfinished primary education & 36.4 \\
$\mathbf{9}$ & Women, unskilled workers, aged under 45 & 18.8 \\
\hline
\end{tabular}

Source: own study based on Secretaria General de l'Esport, 2010, p. 54.

Having defined the groups, we managed to analyze the sports practice characteristics of each group and establish a very clear conduct profile with the help of computer technology and experts in statistics. By way of an example, I have taken two cases to show the level of detail that may be reached and how the information may be organized (Table 4).

Table 4. Profile of people who engage in sports by typologies

\begin{tabular}{|c|c|c|}
\hline & $\begin{array}{l}\text { Group 1: Men, liberal professionals } \\
\text { (high degree of occupation) }\end{array}$ & $\begin{array}{l}\text { Group 9: Women, unskilled workers, } \\
\text { aged under } 45\end{array}$ \\
\hline Designation & Competing* & Weight watching \\
\hline $\begin{array}{l}\text { Sports participation } \\
\text { index }\end{array}$ & $68.4 \%$ & $18.8 \%$ \\
\hline Activities engaged in & $\begin{array}{l}\text { Traditional sports (football, track and field, } \\
\text { basketball, mountaineering, skiing, etc.) and } \\
\text { more contemporary sports (recreational } \\
\text { cycling, fitness gymnastics, etc.) }\end{array}$ & $\begin{array}{l}\text { Recreational swimming and activities such } \\
\text { as aerobics, rhythmic gymnastics, body } \\
\text { expression, gymjazz, step, Pilates, etc. }\end{array}$ \\
\hline Context of practice & $\begin{array}{l}\text { Taking part in competitions, high } \\
\text { proportion of federation licenses and great } \\
\text { associative experience. Activity in clubs. } \\
\text { These individuals travel most away from } \\
\text { their hometown. }\end{array}$ & $\begin{array}{l}\text { Practice on their own initiative and as an } \\
\text { activity in a club or association. This is the } \\
\text { group with the fewest federation licenses. } \\
\text { Practice in municipal facilities, public } \\
\text { spaces, and private centers. }\end{array}$ \\
\hline $\begin{array}{l}\text { Motives for practicing } \\
\text { Motives for not } \\
\text { practicing }\end{array}$ & $\begin{array}{l}\text { Meeting up with friends and competing. } \\
\text { Lack of time, because they dislike sports, } \\
\text { or because they were not taught to practice } \\
\text { sports at school. }\end{array}$ & $\begin{array}{l}\text { To keep in shape and because they enjoy it. } \\
\text { Lack of time is by far the main motive. }\end{array}$ \\
\hline
\end{tabular}

*Each group was assigned a name that referred to its main characteristic.

Source: own study.

Identifying groups of people who engage in sports may also serve as a guide when it comes to devising actions to foster widespread participation in sports. Through such identification, we can learn more about the lifestyles of the people who form part of each group and discover their preferences (when they engage in sports) and motivations, as well as the reasons they give for not practicing sports and their willingness or unwillingness to engage in sports. All this information is of great value for specialists who promote participation in sports and design programs adapted to the socialization characteristics of each group, to whom they send the information in the hope of capturing their attention and encouraging them to participate in sports. 


\section{Sports policy suggestions}

Much has been written on this subject, and, as I mentioned at the beginning of this paper, documentation has been available to us since the 1970s relating research results to the kind of interventions that might be made when devising sports policies:

"Policy demands research to back up choices that need to be made, relying on data to be gathered, mechanisms to be detected, and interventions to be proven effective (...). Sports participation research is in this matter an important instrument to guide and to evaluate policy actions" (Hoekman, 2011, p. 7).

I shall focus on the kind of recommendations I would make on the basis of what I have described above. Needless to say, they constitute only a small contribution to this field of knowledge.

In order for sports participation surveys to be useful, they must provide the means to establish trends. This may be achieved only if they are conducted on a regular basis, approximately every five years, and use the same questionnaire each time; if this varies to embrace social changes, it is advisable that new questions be added and the existing ones remain in their original form. As I was preparing this paper, I came to the realization that the three Eurobarometers are not comparable in many aspects, which is a pity. It is impossible to obtain valuable information unless we, at the very least, can establish the presence of trends. In general, this information is lacking in many countries (Hoekman et al., 2011, p. 8; McPherson, 1984; Hartmann-Tews, 2006, p. 116) ${ }^{3}$.Engaging in longitudinal studies in which the same sample is monitored during an extended period of time strikes me as being not only very difficult and costly, but also unnecessary. On the other hand, the ability to establish trends is indispensable.

Sports policies must strive to make sports available to everyone and counter inequality and difference. To make this possible, programs have to be aimed at target groups. In this way, programs may be adapted to the socialization characteristics of each group and to their body uses. Timetables, spaces, prices, activities, etc. must be appropriate to these aspects in order for groups to identify with the offer. Furthermore, the backup staff must be sufficiently well trained to be sensitive to these questions.

One way to identify target groups is to establish typologies. In the case mentioned above, this was accomplished through segmentation analysis of the sports practice variable. This is a way of integrating all the sociodemographic variables that determine sports participation (age, gender, educational level, socioprofessional category) and evaluating the data relating to each group in order to reach a precise definition of the profile that characterizes them.

In order to ascertain the areas in which sports policies may intervene, we might construct a table featuring the aspects that influence sports practice in each of the established typologies ${ }^{4}$. Each typology corresponds to a social group with a specific habitus, form of socialization, and culture; furthermore, the impact of the individualization process is not the same in all cases. Each group has its own needs, which must be identified if we are to intervene. On the other hand, public sports policies devote most of their efforts to combating inequality and safeguarding respect for difference; some groups will therefore be the object of greater attention than others.

The following table (Table 5) includes a simulation of these suggestions, using the example of the two profiles of people who engage in sports that appear in Table 4.

In conclusion, these intervention policies differ from country to country due to the particularities of sports development. The relationship between the public sector and the voluntary and commercial sectors, a higher or lower degree of intervention in sports on the part of the public sector, the role of volunteers, promotion of sports for all, etc. differ considerably from one country to another (Burriel, \& Puig, 1999; Heinemann, 2003b; Nicholson et al., 2011).

\footnotetext{
${ }^{3}$ Seven surveys were conducted in Spain by Manuel García Ferrando between 1980 and 2010. Quite exceptionally, he used the same questionnaire throughout.

${ }^{4}$ My thanks to Klaus Heinemann for his suggestions on developing this section.
} 
"Each of these dimensions consists of a variety of elements informing social processes and policies relevant to the development of the sport system" (Hartmann-Tews, 2006, p. 121).

Thus, the manner in which sports participation policies are conducted will differ greatly from place to place; nonetheless, what others do may serve as inspiration, though initiatives must be adapted to the particularities of each environment.

Table 5. Areas of sports policy intervention according to typologies of people who engage in sports

\begin{tabular}{|c|c|c|}
\hline & $\begin{array}{l}\text { Group 1: Men, liberal professionals } \\
\text { (high degree of occupation) }\end{array}$ & $\begin{array}{l}\text { Group 9: Women, unskilled workers, } \\
\text { aged under } 45\end{array}$ \\
\hline Diagnosis & $\begin{array}{l}\text { Men who participate in } 68.4 \% \text { of cases and } \\
\text { with sufficient means to do so. Favorable } \\
\text { socialization and habitus environment to } \\
\text { engage in sports. }\end{array}$ & $\begin{array}{l}\text { Women with low purchasing power and } \\
\text { a low percentage of sports participation } \\
(18.8 \%) \text {. Most are responsible for children. } \\
\text { Socialization and habitus environment } \\
\text { unfavorable to engagement in sports. }\end{array}$ \\
\hline Programs & $\begin{array}{l}\text { This group needs no programs, since it is } \\
\text { able to take advantage of existing offers } \\
\text { without the need of special support. }\end{array}$ & $\begin{array}{l}\text { An effort must be made to establish } \\
\text { programs with the following activities: } \\
\text { recreational aerobic swimming, rhythmic } \\
\text { gymnastics, body expression, gymjazz, step, } \\
\text { Pilates, etc. }\end{array}$ \\
\hline Context of engagement & $\begin{array}{l}\text { 1. A sufficient number of facilities } \\
\text { throughout the territory. } \\
\text { 2. Policy of support for clubs and } \\
\text { federations. } \\
\text { 3. Urban and rural public spaces suitable } \\
\text { for sports. }\end{array}$ & $\begin{array}{l}\text { 1. Access to public facilities must be } \\
\text { facilitated through the introduction of } \\
\text { reasonable prices and timetables. } \\
\text { 2. Suitable public spaces without barriers to } \\
\text { access and with safety guarantees. }\end{array}$ \\
\hline Time budget & -- & $\begin{array}{l}\text { Awareness-increasing courses for women } \\
\text { who do not engage in sports so that they } \\
\text { reserve a few hours per week for sports } \\
\text { participation without feeling guilty for not } \\
\text { being entirely at others' disposal. It is } \\
\text { critical to convince them that they are } \\
\text { important, too. }\end{array}$ \\
\hline Economic resources & -- & Prices adapted to their capabilities. \\
\hline
\end{tabular}

Source: own study.

\section{Acknowledgement}

With the support of the Institut Nacional d'Educació Física de Catalunya (INEFC) of the Generalitat de Catalunya (Autonomous Catalan Government).

\section{REFERENCES}

Balbo, L. (1999). L'Europa: (forse) una società-con cura, una società del lifelong learning. Introduzione. /Europe: (Perhaps) a society that cares for you, a lifelong learning society. Introduction/. In L. Balbo et al. (Eds.), Il libro della cura di sé degli altri del mondo /The book of caring for oneself, for others, for the world, pp. 7-20. Turin: Rosenberg \& Sellier.

Bette, H.D. (1995). Deporte e individualización /Sport and individualisation/. In N. Puig (Ed.), Actas del Congreso Científico Olímpico 1992. Sociología del deporte/Proceedings of the 1992 Olympic Scientific Congress. Sociology of Sport/, pp. 327-336. Málaga: Junta de Andalucía, Unisport.

Boltanski, L. (1971). Les usages sociaux du corps/The social uses of the body/, Annales. Histoire, Sciences Sociales, 26(1), 205-233.

Bourdieu, P., Chamboredon, J.C., \& Passeron, J.C. (1991). The craft of sociology: Epistemological preliminaries. Berlin: Walter de Gruyter.

Burriel, J.C., \& Puig, N. (1999). Responsabilidades y relaciones entre el sector público y el privado en el sistema deportivo /Responsibilities and relations between the public and private sectors in the sports system/. In J. Subirats (Ed.), Existe sociedad civil en España? Responsabilidades colectivas y valores públicos IIs there a civil society in Spain? Collective responsibilities and public values/, pp. 178-200. Madrid: Fundación Encuentro. 
Castejón Paz, B., De Dios García Martínez, J., \& Carballada, R. (1973). Rationalising sports policies: Outline of a methodology. Strasbourg: Council of Europe/ Committee for Out-of-School Education \& Cultural Development.

Claeys, U. (1982a). Rationalising sports policies. Sport in European society: A transnational survey into participation and motivation. Strasbourg: Council of Europe/ Committee for the Development of Sport.

Claeys, U. (1982b). Rationalising sports policies. Sport in European society: A transnational survey into participation and motivation (Technical supplement). Strasbourg: Council of Europe/ Committee for the Development of Sport.

European Commission (2004). The citizens of the European Union and sport (Special Eurobarometer, 213). Brussels: European Commission.

European Commission (2010). Sport and physical activity (Special Eurobarometer, 334). Brussels: European Commission.

European Commission (2014). Sport and physical activity (Special Eurobarometer, 412). Brussels: European Commission.

García Ferrando, M., \& Llopis, R. (2011). Ideal democrático y bienestar personal. Encuesta sobre los hábitos deportivos en España 2010 /Democratic ideal and personal wellness. Survey on sporting habits in Spain, $2010 /$. Madrid: Consejo Superior de Deportes. Centro de Investigaciones Sociológicas.

Hartmann-Tews, I. (2006). Social stratification in sport and sport policy in the European Union. European Journal for Sport and Society, 3(2), 109-124.

Heinemann, K. (2003a). Introducción a la metodología de la investigación empírica. En las Ciencias del Deporte /Introduction to empirical research methodology in the sports sciences/. Barcelona: Paidotribo.

Heinemann, K. (2003b). Sport and welfare policies. Six European case studies. Schorndorf: Hofmann \& Schattauer.

Heinemann, K. (2007). Einführung in die Soziologie des Sports (5 ${ }^{\text {th }}$ ed.). /Introduction to the sociology of sport/ Schorndorf: Hoffmann \& Schattauer.

Hoekman, R., Breedveld, K., \& Scheerder, J. (2011). Introduction to the special issue on sports participation in Europe. European Journal for Sport and Society, 8(1-2), 7-13.

McPherson, B.D. (1984). Sport participation across the life cycle: A review of the literature and suggestions for future research. Sociology of Sport Journal, 1(3), 213-230.

Nicholson, M., Hoye, R., \& Houlihan, B. (2011). Participation in sport: International policy perspectives. London: Routledge.

Puig, N., Vilanova, A., Inglés, E., \& Mayo, D. (2009). Hàbits esportius a Catalunya /Sport habits in Catalonia/. Barcelona: Institut Nacional d'Educació Física de Catalunya. Retrieved October 6, 2015, from http://www.observatoridelesport.cat/uploads/pdf/habits2009.pdf

Rodgers, B. (1977). Rationalising sports policies. Sport in its social context: International comparisons. Strasbourg: Council of Europe/ Committee on Sport.

Secretaria General de l'Esport (2010). Enquesta sobre hàbits esportius a Catalunya /Survey on sport habits in Catalonia/. Written by Núria Puig, Adrià Martín, Sílvia González, and Josep Maria Aragay. Barcelona. Retrieved October 6, 2015, from: http://www.observatoridelesport.cat/uploads/pdf/habits2010.pdf

Stamm, H., \& Lamprecht, M. (2011). Swiss sports participation in an international perspective. European Journal for Sport and Society, 8(1-2), 15-31.

Subirats, M. (1998). Con diferencia /With a differencel. Barcelona: Icària, Antrazyt.

UK Sport (1999). COMPASS: Sport participation in Europe. London: UK Sport.

Van Bottenburg, M., Rijnen, B., \& Van Sterkenburg, J. (2005). Sport participation in the EU: Trends and differences. Amsterdam: Mulier Institute. 
AUTHOR'S ADDRESS: Núria Puig

National Institute of Physical Education of Catalonia

GISEAFE (Group of Social and Educational Research

in Physical Activity and Sport)

Avinguda de l'Estadi 12-22

08038 Barcelona, Spain

E-mail: nuriapuiginefc@gmail.com

Received: 15 February 2016; Accepted: 15 March 2016 